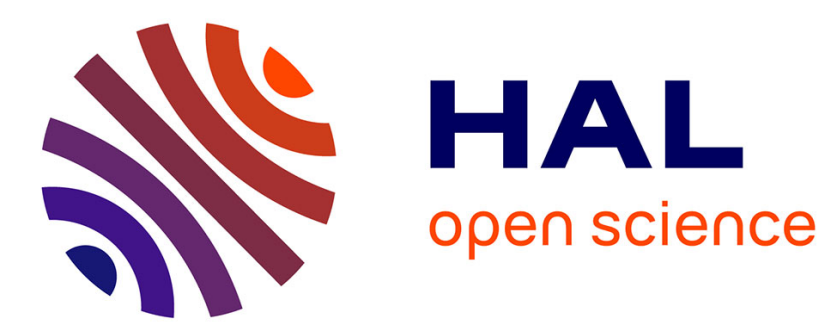

\title{
Migration as an antidote to rent-seeking?
}

Fabio Mariani

\section{To cite this version:}

Fabio Mariani. Migration as an antidote to rent-seeking?. Journal of Development Economics, 2007, 84 (2), pp.609-630. 10.1016/j.jdeveco.2007.02.001 . halshs-00186460

\section{HAL Id: halshs-00186460 \\ https://shs.hal.science/halshs-00186460}

Submitted on 9 Nov 2007

HAL is a multi-disciplinary open access archive for the deposit and dissemination of scientific research documents, whether they are published or not. The documents may come from teaching and research institutions in France or abroad, or from public or private research centers.
L'archive ouverte pluridisciplinaire HAL, est destinée au dépôt et à la diffusion de documents scientifiques de niveau recherche, publiés ou non, émanant des établissements d'enseignement et de recherche français ou étrangers, des laboratoires publics ou privés. 


\title{
Migration as an antidote to rent-seeking?*
}

\author{
Fabio Mariani \\ UNIVERSITÉ PARIS 1 PANTHÉON-SORBONNE ${ }^{\dagger}$
}

This draft: January 2007

\begin{abstract}
We develop a new mechanism through which skilled migration may influence economic performance in the sending country. If agents can choose between acting as rent-seekers and engaging in productive activities, and only productive skills are exportable, a positive probability of migration (to a more secure economy) reduces the relative expected returns from rent-seeking, thus decreasing the proportion of skilled workers who opt for "parasitic" activities. Such an improvement in the allocation of talent may prevail over the loss of skilled workers due to outmigration. However, we show that this result is not robust to the introduction of endogenous protection. If productive workers share their resources between accumulation of productive capital and investment in security, prospective migration may induce a weaker protection against rent-seeking, which in turn might depress average income in the source economy.

JEL classification: D72; F22; O1.

Keywords: Rent-seeking; Skilled migration.
\end{abstract}

\section{Introduction}

Rent-seeking and skilled migration (the so-called "brain drain") are two common features of less developed economies. Rent-seeking can take different forms: corruption, bribery, excessive bureaucracy, crime, insufficient protection of property rights, lack of political culture and meritocracy, malfunctioning institutions, etc. As shown by Mauro (1995), who supplies some data on the diffusion of corruption (and the like) around the World, developing countries are severely affected by this kind of pathology. On the other hand, Docquier and Marfouk (2004) provide estimates of migration rates by skills and by sending country:

\footnotetext{
*I am thankful to Raouf Boucekkine, Claude d'Aspremont, David de la Croix and Matthias Doepke for their precious comments on earlier drafts. The Co-Editor of this Journal, Gordon Hanson, and two anonymous referees provided very helpful suggestions. I would also like to express my gratitude to seminar participants at UCL (Louvain-la-Neuve), University of Auckland, FUNDP (Namur) and University of Evry for useful discussion. All remaining errors are, of course, under my own responsibility. Financial support from the Belgian French-Speaking Community in the framework of the ARC Project "New Macroeconomic Perspectives on Development" (Grant ARC 03/08-302), and from the Centre Cournot pour la Recherche en Economie ("Robert Solow" Scholarship) is very gratefully acknowledged.

${ }^{\dagger}$ CES - Centre d'Economie de la Sorbonne; 106-112, bd. de l'Hôpital, F-75013 Paris (France). Ph.: +33 (0)1 44078350; fax: +33 (0)1 44078231. E-mail: fabio.mariani@univ-paris1.fr.
} 
they observe that less developed countries display the highest brain drain rates and that, in most cases, skilled migration has been increasing over the 1990-2000 decade.

Both of these problems are usually considered to be harmful for growth and economic performance. Concerning rent-seeking, there is wide agreement that it exerts an adverse effect on development; it can determine, for instance, a misallocation of productive abilities, a wasteful employment of resources, or a decrease in investment rates (see Bardhan (1997) for a survey, and Mauro (1995) for an empirical assessment). Skilled migration as well, since the pioneering contribution of Bhagwati and Hamada (1974), has usually been regarded as a threat to economic growth and considered as an impoverishing flight of human capital. More recently, several models of brain drain have challenged this view, pointing out that a positive, although limited, emigration rate may be beneficial for the source economy: the opportunity to migrate would raise the relative expected returns to higher education, thus determining an inducement effect on schooling decisions; this brain gain (in terms of higher average human capital) may prevail over the actual brain drain. As examples of this new approach, we can cite Mountford (1997), Stark and Wang (2002) and Beine et al. (2001).

However, until now theoretical models have studied rent-seeking and skilled migration separately, without trying to establish a link between the two problems. Thus, the possible consequences of their interaction for economic development have been neglected.

In the present paper we want to allow for such an interaction and see how migration prospects may influence rent-seeking. To do that, we follow several models of rent-seeking like Acemoglu (1995), Murphy et al. (1993), Torvik (2002), Mehlum et al. (2003), Baland and François (2000), and study the endogenous career choice between carrying out productive (entrepreneurial) activities and engaging in parasitic activities (rent-seeking). In this kind of framework, we introduce a new mechanism: given that productive skills are typically less country-specific and more exportable than rent-seeking abilities, a positive probability of migration to a richer and more "virtuous" country can decrease the relative expected returns to rent-seeking and therefore reduce the attractiveness of this career option, thus leading to a smaller proportion of rent-seekers in the source economy. We find that this more favorable allocation of talent can more than compensate the loss of skilled workers due to outmigration and a positive income-maximizing migration rate does exist.

We also check how the picture changes once we allow for endogenous protection: productive agents may in fact employ some of their resources to impede predation, thus reducing the fraction of income that rent-seekers can take away from them. In such a case, probabilistic migration to a country with less rent-seeking may weaken the incentive to raise defensive barriers, in favor of the accumulation of "portable" skills ${ }^{1}$. Therefore, after migration, rent-seeking may be less widespread but more effective, so that the net effect of migration on income becomes ambiguous: we identify some conditions under which the

\footnotetext{
${ }^{1}$ Broadly speaking, prospective migration might induce "weaker institutions" in the sending country: since they plan to work abroad, productive agents care less about the future quality of economic institutions at home.
} 
result of beneficial migration can be reversed.

Our theoretical results are partly supported by existing data. We will show that, for a cross-section of countries, it is possible to detect a positive (negative) correlation between brain drain rates and the proportion of people who get engaged in productive (rentseeking) careers, while the brain drain does not appear to be negatively correlated with the after-migration total incidence of rent-seeking.

Let us also underline that our explanation for a beneficial brain drain is entirely new: in fact, we look at a wasteful allocation of talent as a factor of underdevelopment, while the existing literature on brain drain and growth has focused on the insufficient accumulation of human capital. In both approaches there is room for a potentially beneficial effect of migration, since the probability of migration is higher for the more productive group (entrepreneurs vs rent-seekers, skilled vs unskilled), whose endogenous size is thus positively affected. However, the two underlying mechanisms are very different ${ }^{2}$.

Finally, the kind of analysis we are going to develop can be also related to a couple of papers by Docquier and Rapoport (2003a, b) on migration and ethnic discrimination. They study the effects of skilled migration on an economy populated by two groups - an ethnic minority and a dominant ethnic group - of exogenous size, with the majority levying a discriminative tax on the educated minority. However, our work looks at a different kind of rent-extraction (unrelated to ethnic discrimination), treats the relative size of the groups as endogenous (it being the result of a career choice, and not the deterministic consequence of ethnic identity), and introduces the possibility of self-protection by the vexed group.

The paper is then organized as follows. After this Introduction, Section 2 is devoted to the presentation of some stylized facts on the relation between skilled migration and rent-seeking. Section 3 presents and solves the basic model. Endogenous protection and its implications are analyzed in Section 4. Section 5 extends the model to allow for an endogenous probability of migration. Finally, Section 6 concludes.

\section{Stylized facts}

Here, we want to use available cross-country data to check whether rent-seeking and the probability of migration are correlated. Consistent with what has been put forward in the Introduction, we look at two different aspects of rent-seeking: (i) the allocation of talent between rent-seeking and productive activities, that is the relative number of people engaged in the two careers ${ }^{3}$, and (ii) the total incidence of rent-seeking, which takes also into account the intensity of rent-seeking (i.e. the fraction of income that parasitic agents take away from productive workers), and not only the size of the rent-seeking sector as measured by the number of people who have opted for a rent-seeking career.

\footnotetext{
${ }^{2}$ In our model, the inducement effect determined by a positive chance of emigration acts through "less rent-seeking", instead of "higher education".

${ }^{3}$ The expressions "allocation of talent" and "career choice" will be used interchangeably.
} 


\subsection{Skilled migration and career choices (allocation of talent)}

As a proxy for the probability of (skilled) migration, we use the migration rate for people with tertiary education or more, which we will sometimes refer to as the brain drain rate throughout this Section. Data on migration rates by skills are provided by Docquier and Marfouk (2004) for a sample of about 200 countries.

To account for the allocation of talent, we follow Murphy et al. (1991), who use college enrollment in law as a measure of talent allocated to rent-seeking, and college enrollment in engineering as a proxy for talent allocated to entrepreneurship. Notwithstanding some evident limits ${ }^{4}$, an indicator of this type, focusing on educational choices, captures quite well the responsiveness of agents to the relative returns of alternative career options. Although the source is the same - enrollment in tertiary education by field (UNESCO, 1998, 1999, 2006), our measure of the allocation of talent between alternative careers is slightly different from Murphy et al. (1991); more precisely, we use enrollment in the fields of sciences and engineering ${ }^{5}$ as a proxy for the choice of a productive career, while to quantify how many people opt for a rent-seeking career we consider enrollment in both law and religion $^{6}$, since in several developing countries a sizable part of the bureaucracy has a religious formation and quite often religious leaders act as rent-seekers.

We start by plotting tertiary education enrollment in the fields of science and engineering (in 1995 ${ }^{7}$ ) against brain drain rates (as of 1990) for the largest possible cross section of countries $^{8}$. The five-year lag has been chosen to deal with possible reverse causality issues: a sizable brain drain may in fact be explained by an excess supply of productive skilled workers. Moreover, in such a way most of the students are supposed to have taken the decision about their field of specialization using also the information they had on current migration possibilities. Figure 1 shows some positive correlation: countries with higher skilled-migration rates are characterized by a higher fraction of students going for education in "productive" fields. To summarize:

Stylized fact 1 Specialization in productive fields is positively correlated with skilled migration.

Figure 2 unveils the other side of the story: where the probability of migration is smaller, there is a less favorable allocation of talent, and a larger fraction of people chooses to get

\footnotetext{
${ }^{4}$ Most lawyers and civil servants are supposed to be productive workers, and some bureaucracy is necessary for the efficient functioning of an economic system.

${ }^{5}$ Sciences are: maths, computer sciences, natural sciences and health-related sciences. Engineering and architecture are counted together.

${ }^{6}$ Religion is counted together with humanities and fine arts.

${ }^{7}$ We have chosen 1995 (or the closest year, when data for 1995 are not available) since UNESCO data have not the same degree of disaggregation in more recent years (2000 and 2004): for instance, it is not possible to know exactly how many students are enrolled in law, since the new "broad field" of aggregation puts together law, business and social sciences.

${ }^{8}$ Subject to the following constraints: (i) the reliability rate of the brain drain estimates, as reported by Docquier and Marfouk (2004, p.27), must be higher than 80\%, (ii) as suggested by Murphy et al. (1991, p. 523), only countries with more than 10000 students are included in the sample.
} 


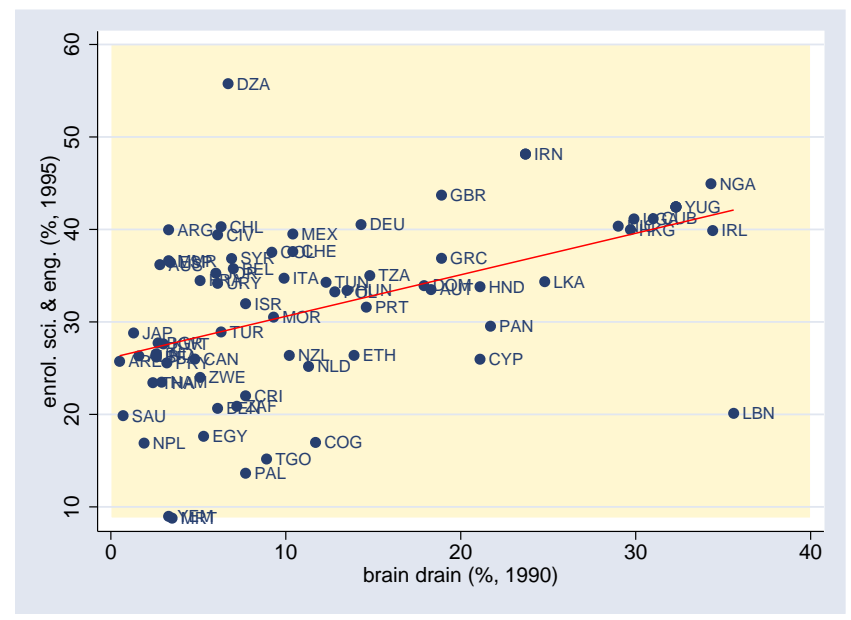

Figure 1: Brain drain and enrollment in productive fields for a cross-section of 68 countries trained for rent-seeking jobs (law and religion, in our approximation). In other words:

Stylized fact 2 Specialization in rent-seeking fields is negatively correlated with skilled migration.

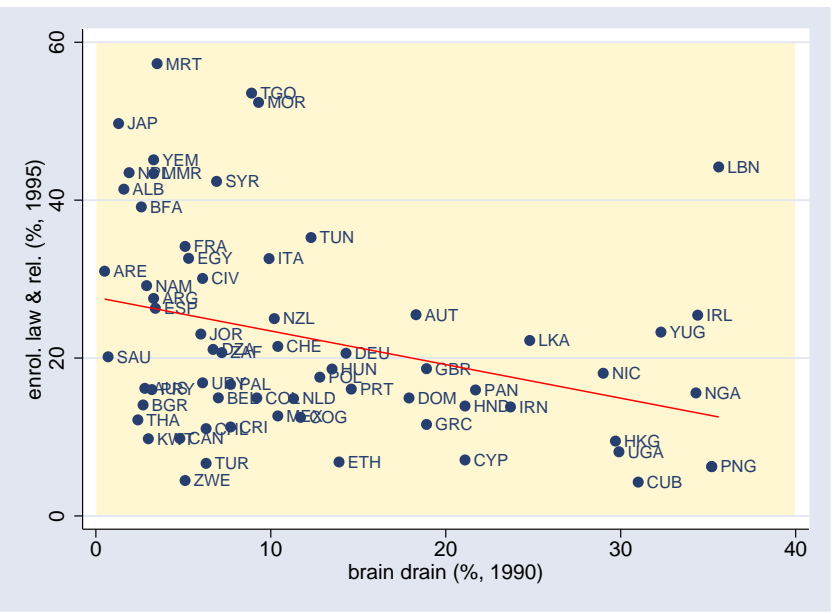

Figure 2: Brain drain and enrollment in rent-seeking fields for a cross-section of 65 countries

To summarize, we may say that available data seem to support the idea that a higher migration probability corresponds to a better allocation of talent ${ }^{9}$.

\subsection{Skilled migration and corruption ("perceived" rent-seeking)}

In the Introduction, while talking about endogenous protection, we have put forward that the total amount of rent-seeking can be higher after migration, even if the relative size of

\footnotetext{
${ }^{9}$ Before going on, let us underline that Figures 1 and 2 are built using all the available information, and not only data relative to less developed countries. However, if we remove the most industrialized countries from the sample, and keep only LDC's, the quality of the results does not change: moreover, correlations are even more evident. Results are also more clear-cut if we split the whole cross-section in regional subsamples (America, Africa, Asia-Pacific and Europe). All this additional evidence is available upon request.
} 
the rent-seeking sector is reduced (i.e. even if a smaller proportion of workers has chosen the "parasitic" career). But, how can we measure the total incidence of rent-seeking? A suitable solution is represented by the Corruption Perception Index (CPI), published by Transparency International ${ }^{10}$, which describes " ... how international businessmen and financial journalists perceive corruption ..." in different countries around the World. As it is built, this index takes into account both the size of the rent-seeking sector and the intensity of rent-seeking activities (corruption). Since the CPI score measures transparency, on a 0-10 scale, we use $(10-C P I)$ as a proxy for rent-seeking.

Figure 3 shows that the correlation between skilled migration rates (in 2000) and perceived rent-seeking (in 2005) is even, although weakly, positive. However, for brain drain rates lower than $20 \%$, it is almost impossible to identify any kind of correlation. We are then able to state the following:

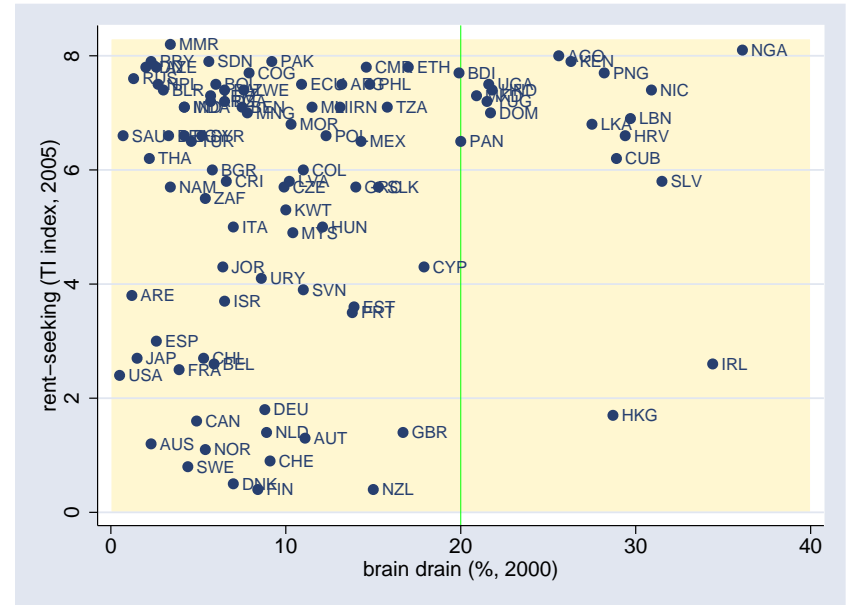

Figure 3: Brain drain and corruption (TI) for a cross-section of 95 countries

\section{Stylized fact 3 There is no obvious correlation between corruption and skilled migration.}

This confirms our guess that the allocation of talent to parasitic activities and the total incidence of rent-seeking (corruption) may indeed follow different trajectories, thus justifying an extension of our theoretical model to take into account endogenous protection.

Before going on, let us underline that a reverse causality is more than likely to play a role in explaining a part of the relationships described in Figures 1-3. However, our theoretical model only focuses on the effects of migration on rent-seeking.

\section{The benchmark model}

We start by considering a simple setting with exogenous protection: workers engaged in productive activities cannot influence, by their choices, the fraction of income they lose

\footnotetext{
${ }^{10}$ Data are available on-line at http:/ / www.transparency.org/policy_research/surveys_indices/cpi.
} 
when they are subject to rent-seeking pressures.

\subsection{Autarky}

We introduce a simple model of rent-seeking à la Acemoglu (1995). The economy is populated by homogeneous agents (workers). Each worker is endowed with a productive capacity $h$, that we can assimilate to human capital, and is allowed to make a (career) choice between engaging in productive activities and becoming a rent-seeker ${ }^{11}$. Then, if she chooses to become a productive worker, she will be able to produce (gain) $h$ unities of income. However, part of this income may be lost due to the effect of rent-seeking aggression by parasitic agents. More precisely, we model the rent-seeker/producer interaction as a matching process: every producer may deal with at most one rent-seeker, who will take away an exogenous fraction $q$ (with $0<q<1$ ) of her product ${ }^{12}$; we will refer to $q$ as the "extortion rate" associated with rent-seeking. If an agent decides to act as a rent-seeker, and if she actually comes in contact with a productive worker, she will earn a rent $q h$.

As a consequence of the matching process, we have that if rent-seekers exceed producers in size, there will be someone among the former who will not find any productive workers to predate. If the opposite is true, with rent-seekers being outnumbered by producers, there will be some of the latter who will avoid extortion.

We identify by $p$ and $(1-p)$ respectively the fraction of rent-seekers and the fraction of productive workers that coexist in the economy. The equilibrium value of $p$ arises endogenously as a consequence of the career choice: it is determined as a value which equates expected incomes from the two activities (agents are assumed to be risk-neutral). The expected revenue of the representative entrepreneur ${ }^{13}$ would be:

$$
\pi_{E}(p)=\left\{\begin{array}{ccc}
\left(1-q \frac{p}{1-p}\right) h & \text { if } & p<\frac{1}{2} \\
(1-q) h & \text { if } & p \geq \frac{1}{2}
\end{array} .\right.
$$

With $p=0$, entrepreneurs would be able to keep all their production. Thereafter, an increase in $p$ would result in an increased probability $p /(1-p)$ to "meet" a rent-seeker, and then in a lower expected income. Finally, if $p \geq 1 / 2$, predators are more numerous than prey, and entrepreneurs keep only a fraction $(1-q)$ of their production, regardless of $p$.

From the point of view of parasitic agents, they are sure to meet a productive agent, collecting $q h$, as long as $p \leq 1 / 2$. For $p>1 / 2$, a crowding-in effect (acting through a decreasing probability $(1-p) / p$ to be matched with a productive worker) will progressively

\footnotetext{
${ }^{11}$ In the real world, however, the same individual might carry out both rent-seeking and productive activities: the fact that a bureaucrat collects bribes cannot exclude that she also performs some productive tasks.

${ }^{12}$ For instance, we may think of a corrupted bureaucrat asking for a bribe or simply of extortion carried out by an organized crime group.

${ }^{13}$ Throughout the rest of the paper, we will sometimes use the term "entrepreneur" to label the representative productive worker, although she gains her income from her human capital, and not from physical capital.
} 
erode parasitic rents down to 0 (for $p$ tending to 1$)^{14}$. Therefore, rent-seekers' profits can be expressed as:

$$
\pi_{R S}(p)=\left\{\begin{array}{ccc}
q h & \text { if } & p<\frac{1}{2} \\
q \frac{1-p}{p} h & \text { if } & p \geq \frac{1}{2}
\end{array} .\right.
$$

We assume that career choices are endogenous and irreversible, so that each worker has to choose once and for all whether to engage in productive or parasitic activities.

If $q<1 / 2$ there will not be any rent-seeking in the economy, since the entrepreneurial career will turn out to be, for any $p$, more rewarding than the rent-seeking activity. But, assuming that $q>1 / 2$, there will always be a positive fraction of rent-seekers in the economy, and multiple equilibria may arise, as shown in Figure 4. Murphy et al. (1993), Acemoglu (1995), Torvik (2002) and Mehlum et al. (2003), although resting on different explanations, end up with the same kind of picture. And, as it has been widely discussed in those papers, only one of the two equilibria with positive rent-seeking is stable (point $E_{1}$ in Figure 4$)^{15}$. Our further analysis will focus on equilibria like $E_{1}$; being characterized by a high fraction of rent-seekers, they also better fit the case of less developed countries.

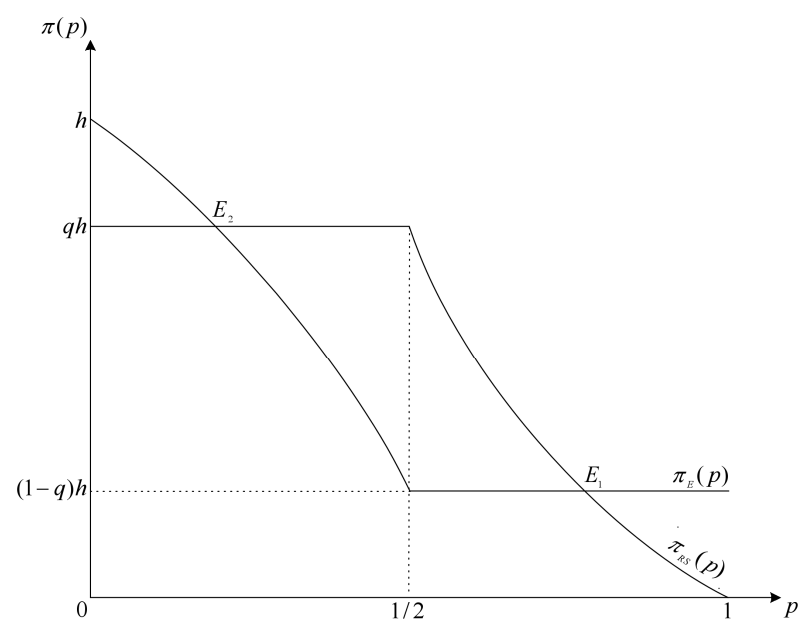

Figure 4: The allocation of talent: multiple equilibria

Solving $\pi_{R S}=\pi_{E}$, we can see that the high rent-seeking equilibrium we are dealing with is characterized by $p=q$. An equilibrium like $E_{2}$ would imply $p=1-q$.

\footnotetext{
${ }^{14}$ However, if we assume (somewhat more realistically) that each rent-seeker can deal with $\eta(>1)$ entrepreneurs at once, the threshold value moves from $1 / 2$ to $1 /(1+\eta)$.

${ }^{15}$ The stability analysis runs as follows (see for instance Murphy et al., 1993). Consider an equilibrium like $E_{2}$, and suppose now to be in a right neighborhood of $E_{2}$ : in this case returns to rent-seeking would be higher than returns from productive activities, more workers would rationally choose to become rent-seekers, $p$ grows larger and the economy would be driven to $E_{1}$. On the other side, assume that the economy is in a left neighborhood of $E_{2}$; in such a case expected income from entrepreneurship exceeds expected rents, workers would have an incentive to get engaged in the productive career, and the economy would be driven toward a state with no rent-seeking at all $(p=0)$, which may also be considered as a stable equilibrium, technically speaking. In a right neighborhood of $E_{1}$, instead, profits would be larger than rents, justifying an incentive to choose entrepreneurship: by consequence $p$ would decrease, leading the economy back to $E_{1}$.
} 


\subsection{Migration}

To introduce migration, we assume that every agent who decides to work in the productive sector has a positive chance of emigration $m$, while migration is not allowed for rent-seekers. As we have already put forward in the Introduction, this assumption is not unrealistic, since rent-seeking skills are very likely to be strongly country-specific, while productive skills are not. In fact, high-skilled migration typically concerns scientists and engineers, and not civil servants, lawyers and bureaucrats ${ }^{16}$.

Migration may be motivated by different reasons. Roughly speaking, the opportunity to earn higher wages, net of migration costs and eventual skill depreciation, is the main reason for labor mobility. However, many different factors may lie behind wage differentials. Since we want to focus on the rent-seeking issue, we put aside technological explanations, and assume that the foreign country is attractive because it protects property rights and/or labor income more effectively than the sending country, so that $q_{F}<q$. In Docquier and Rapoport's (2003) paper, wage differentials were neglected as well, to privilege an explanation of migration based on the attractiveness of a discrimination-free country (from the viewpoint of the ethnic minority).

The migration rate $m$, that for the moment we assume to be exogenous, can be determined by both internal and external policies. The emigration policy of the sending country may in fact aim at controlling migration outflows, but it is more obvious to think that international mobility is restricted by immigration authorities in the destination countries, using instruments like quotas, visa policies, etc. Whatever the case, in the sending country productive workers face uncertainty in the sense that they have a probability $m$ to be accepted in the destination country, while with a probability $(1-m)$ they will be forced to stay home ${ }^{17}$.

Once probabilistic migration is taken into account, and assuming for the sake of simplicity that after migration the number of rent-seekers will continue to exceed the number of entrepreneurs, the expected income of the representative entrepreneur would be given by:

$$
\pi_{E}(p, m)=\left[(1-m)(1-q)+m\left(1-q_{F}\right)\right] h,
$$

while rent-seekers would expect to gain:

$$
\pi_{R S}(p, m)=q \frac{(1-m)(1-p)}{p} h .
$$

\footnotetext{
${ }^{16}$ A very nice example is provided by Murphy et al. (1991): Talleyrand was a bishop with a large tax income in France, but when he escaped to the United States he acted as a successful entrepreneur. This is indeed a case of "career crossover" that we will not consider (career choices are irreversible in our setting), but illustrates quite well how even the brightest rent-seeking skills are not exportable. However, rent-seekers may be foreignraised, as it still happens in many LDC's.

${ }^{17}$ Being homogeneous, productive workers are randomly selected for migration. Otherwise, prospective migrants are likely to undergo some kind of selection by skills.
} 
Probabilistic migration raises expected profits (through prospective foreign income) and decreases rents (through tougher crowding-in: predators have a lower probability to meet prey). As a consequence, we obtain the following Proposition:

Proposition 1 When the extortion rate $q$ is exogenous, probabilistic migration to a more virtuous country has a "moralizing" effect on the allocation of talent in the home economy.

In fact, equating entrepreneurial profits (3) and rents (4), we get:

$$
p_{M}(m)=\frac{(1-m) q}{1-m q_{F}}
$$

which is lower than the proportion of rent-seekers without migration, $p$. However, only a fraction $(1-m)$ of the $\left(1-p_{M}\right)$ productive workers remains in their home country, and the after-migration predator/prey ratio becomes:

$$
\gamma_{M}(m)=\frac{q}{1-q+m\left(q-q_{F}\right)}
$$

which is always decreasing in $m$, and then it is lower than it would have been without migration $(\gamma=q /(1-q))$. Therefore, probabilistic migration to a country with less rentseeking induces a more favorable allocation of talent in the home economy.

This finding, suggesting that more migration implies less rent-seeking, echoes Docquier and Rapoport's (2003) results, according to which migration prospects have a "protective" effect on the minority. However, in their model this effect runs through a lower discrimination tax rate, while in ours predation is not weaker ( $q$ is unaffected), but only less diffuse.

\subsection{An optimal migration rate?}

Above, we have been able to isolate a beneficial impact linked to general migration. However, if we think that the rent-seeking/production career choice concerns specially highskilled workers, we could easily interpret it as a brain gain linked to high-skilled migration. Different from the existing literature (see for instance Mountford, 1997, Beine et al., 2001, or Stark and Wang, 2002), this positive effect is not related to the accumulation of human capital through education. However, dealing with homogeneous agents, we have not considered the possible brain drain effect, i.e. the potential shrinking of the highly educated group due to migration opportunity. To cope with this problem, we can build a very simple extension of our basic model, introducing explicitly heterogeneity by skills.

More precisely, we assume that in our model economy there is also a class of low-skilled individuals. These agents are not given the choice to become rent-seekers, since the extraction of rents is assumed to require skilled labor ${ }^{18}$. As workers, they are characterized by a very low productivity that allows them to produce only at a subsistence level, so that their

\footnotetext{
${ }^{18}$ As in the case, for instance, of corrupted bureaucrats.
} 
net income is equal to zero; as subsistence producers, they are ignored by rent-seekers ${ }^{19}$. We assume that, before migration, for every skilled agent (rent-seeker or entrepreneur) there are $\chi$ subsistence producers in the economy.

In such a stylized setting, we can look for an optimal (e)migration rate, i.e. that value $m^{*}$ of $m$ which maximizes a desirable objective function. We can propose two alternative formulations for the objective function:

(i) the total number of productive skilled workers left in the home economy, that is given by $(1-m)\left(1-p_{M}(m)\right)$;

(ii) the after-migration average income of honest workers (productive skilled workers and subsistence workers), i.e.

$$
\frac{(1-m)\left[1-p_{M}(m)\right](1-q) h}{(1-m)\left[1-p_{M}(m)\right]+\chi} .
$$

Maximizing $(1-m)\left(1-p_{M}\right)$ could be desirable since growth, or prospective economic performance in the sending economy may depend on the number of high-skilled, productive workers in the country ${ }^{20}$; it is also the simplest way to encompass both the brain drain (through $(1-m)$ ) and the brain gain (through $\left(1-p_{M}\right)$ ). Option (ii) looks like a very natural solution to identify an optimal $m$, it being very much in the spirit of a utilitarian welfare function, where the utility (income) level of every group is weighted by its relative size.

It could also be interesting to consider a third kind of objective function: the aftermigration average income (including rents in the count). Such an objective would deserve some attention as long as the identity of rent-seekers and entrepreneurs is anonymous $a$ priori, and the social planner feels committed to maximizing the well-being of the whole population, regardless of their career choice: this case will be analyzed in Appendix $\mathrm{B}^{21}$.

However, we believe that functions (i) and (ii) are more interesting if we think that the policy maker, on purely ethical grounds, should not care too much about the welfare of the parasitic group; in this case the following Proposition holds:

Proposition 2 With probabilistic migration and an exogenous $q$, a strictly positive optimal migration rate does exist, if the intensity of rent-seeking in the foreign economy is sufficiently low.

In fact, under both objective functions (i) and (ii), $m^{*}$ is given by:

$$
m^{*}=\max \left[0 ; \frac{1-\left(1-q_{F}\right) \sqrt{\frac{q}{q-q_{F}}}}{q_{F}}\right],
$$

and it is easy to check that $m^{*}$ is strictly positive if $q_{F}<2-(1 / q)$.

\footnotetext{
${ }^{19}$ In analogy with Docquier and Rapoport (2003): in their paper, uneducated minority members remain at the subsistence level, thus escaping discriminatory taxation.

${ }^{20}$ Following for instance Mountford (1997), who considers an economy-wide growth externality which is assumed to depend on the relative number of educated workers.

${ }^{21}$ To some extent, it could also have been interesting to include the welfare of successful migrants in the objective function. However, in conformity with the existing literature, we prefer to limit our analysis to the sending economy, to which emigrants do not belong any more.
} 
It is interesting to notice that, if migration is allowed to a rent-free country $\left(q_{F}=0\right)$, there will always be a positive migration rate which maximizes income (or growth) in the source economy. It is in fact given by $m^{*}=1-1 / 2 q$.

Moreover, it is worth noting that $m^{*}$ is increasing in $q$ : the higher the extortion rate in the sending economy, the larger the optimal migration rate $^{22}$.

\section{Endogenous protection}

The results we obtained in the previous Section look quite encouraging about a possibly beneficial brain drain. Now, we want to check whether this kind of finding is robust to the introduction of endogenous protection. Until now we have in fact assumed both $q$ and $h$ to be exogenous, but this need not necessarily be the case. We could instead imagine that there is a trade-off between the two. For example, in the case of physical capital, we may say that the entrepreneur, before setting up her business, has to decide how to allocate her resources between productive investments (machineries) and investments in protection (like building walls to defend her property, hiring and training guards, or financing better institutions). In the case of human capital, the scarce resource may be thought of as being time, which can be allocated between accumulation of human capital (through education or whatsoever) and some sort of political activity devoted to obtaining better protection of property rights or to building a safer net of relationships (with bureaucrats, for instance). Regardless of their nature, investments in protection are supposed to determine a lower $q$. And in any case, a positive probability of migration to a more secure country will induce entrepreneurs to invest more in productive skills and less in defensive activities, since they obviously care less about security and the quality of institutions in their home country. As a consequence, after migration the home economy may end up with a higher proportion of productive workers (smaller size of the rent-seeking sector, $p$ ), but more intensity in predation (higher $q$ ).

\subsection{The extended model: autarky vs migration}

To take explicitly into account the choice between these two different types of investments productive or defensive, we can give our model a simple two-period structure. The timing of events goes as follows: the irreversible career choice is made at the beginning of the first period $(t)$, actual production and interactions between rent-seekers and entrepreneurs take place during the second period $(t+1)$, while uncertainty about migration is cleared at the beginning of the second period.

\footnotetext{
${ }^{22}$ In Appendix B we will also show that, not surprisingly, the optimal migration rate would be higher if rents were included in the objective function. When adding rent-seekers to the computation of average income, there is no additional "drain effect" to be accounted for: parasitic agents do not migrate and average rents, depending directly on the predator/prey ratio, are always increasing in $m$
} 
Therefore, the investment choice takes place before uncertainty about migration is cleared. This is crucial for all the results that will be derived in this Section. An alternative timing of events, with productive workers deciding about their protection effort after uncertainty about migration is resolved, might be considered. However, it would not add anything interesting to our previous analysis (carried out in Section 3 and based on an exogenous $q$ ), since the investment in protection would not depend on the probability of migration ${ }^{23}$.

We also assume that during the first period every skilled worker who wants to engage in productive activities is endowed with one unit of time: a fraction $x_{t}$ of this time can be invested to build up future productive capacity according to $h_{t+1}=x_{t}^{\alpha}$, where $0<\alpha \leq 1$; the remainder of the time $\left(1-x_{t}\right)$ can be used to reduce $q_{t+1}$ through a defensive effort ${ }^{24}$. Dropping time indexes, the function $q_{t+1}=f\left(1-x_{t}\right)=F\left(x_{t}\right)$ can be specified as:

$$
q(x)=\max \left[\bar{q}-(1-x) \rho ; \frac{1}{2}\right]
$$

where $1 / 2<\bar{q} \leq 1$ and $\rho \geq 0$. The parameter $\rho$ accounts for the productivity of the defensive effort $(1-x)$ in reducing the fraction of income that is lost due to rent-seeking, as well as the opportunity cost of shifting resources from protection to accumulation of productive skills; in this sense $\rho$ may be related to the quality of institutions in the economy. It is easy to check that: $\lim _{x \rightarrow 0} q(x)=\max [\bar{q}-\rho ; 1 / 2]$ and $\lim _{x \rightarrow 1} q(x)=\bar{q}$.

The function $q(x)$ is depicted in Figure 5: the parameter $\rho$ is crucial for determining its slope. We would underline that for $\rho=0$ the case of exogenous protection is reproduced: $q=\bar{q}$ does not depend on $x$. The lower bound $1 / 2$ is binding as long as $\rho>1 / 2$.

We assume for simplicity $\bar{q}=1$. If no time is devoted to defense, the rent-seeker will take all the production away from the worker; if all the time is spent building up defenses, $q$ may be driven down to $1 / 2$ (entrepreneurs are not able to completely eliminate rentseeking relying only on their defensive effort). The representative worker will choose optimally $x$, in order to maximize her expected profits net of rent-seeking, that amount to $(1-q(x)) x^{\alpha}$.

In autarky the optimal choice would be

$$
x^{*}=\left\{\begin{array}{ccc}
\alpha /(1+\alpha) & \text { if } & \rho \leq 1 / 2 \\
\max [\alpha /(1+\alpha) ; 1-1 / 2 \rho] & \text { if } & \rho>1 / 2
\end{array} .\right.
$$

The possibility of corner solutions in the second case is due to the fact that it is never optimal to select an $x$ lower than $1-1 / 2 \rho$, since the implied decrease in production would not determine any gain in protection (see Figure 5). To rule out this possibility (when $\rho>1 / 2$ ),

\footnotetext{
${ }^{23}$ Under the assumption that rent-seekers continue to outnumber producers.

${ }^{24}$ We do not model explicitly neither the choice of the aggressive effort made by the rent-seeker, nor her accumulation of skills. Grossman and Kim (1995) have a closed-economy model with endogenous efforts on both the defensive and the offensive side. Docquier and Rapoport $(2003 a, b)$ consider that the discriminative tax rate (that in their models plays the same role played by $q$ in ours) is chosen by the rent-seeking ethnic majority and cannot be influenced by the minority.
} 


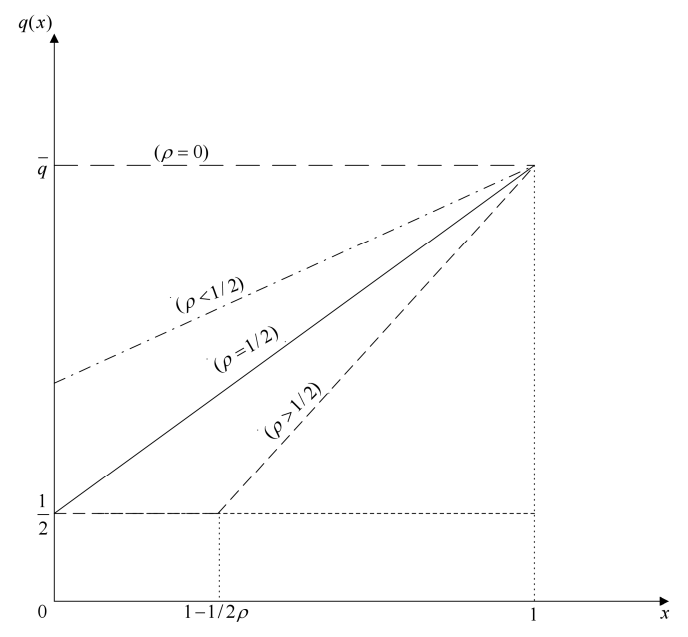

Figure 5: The function $\mathrm{q}(\mathrm{x})$

we would simply need to impose an upper bound to the values that the parameter $\rho$ may assume, namely $\rho \leq(\alpha+1) / 2$.

If the possibility of migration is taken into account, the fraction of time devoted to human capital accumulation becomes:

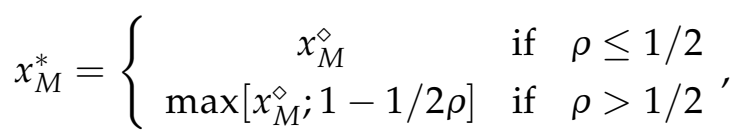

where

$$
x_{M}^{\diamond}=\min \left[\frac{\alpha\left[m\left(1-q_{F}\right)+(1-m) \rho\right]}{(1+\alpha)(1-m) \rho} ; 1\right] .
$$

Notice that $x_{M}^{*}=x_{M}^{\diamond}$ as long as $\rho \leq \bar{\rho}$, where:

$$
\bar{\rho}=\frac{(\alpha+1)-m(1-\alpha)-2 m \alpha q_{F}}{2(1-m)}
$$

while, to rule out corner solutions $\left(x_{M}^{*}=1\right)$, we would simply need $m$ to be lower than $\bar{m}=\rho /\left[\alpha\left(1-q_{F}\right)+\rho\right]$. Throughout the remainder of this Section, we will assume, for ease of presentation, that both $\rho \leq \bar{\rho}$ and $m<\bar{m}$ hold.

It is easy to see that $x_{M}^{*}$ is a decreasing function of $q_{F}$, while it increases with $m$ : more security abroad or a higher probability of migration, both these factors induce weaker investments in protection and more accumulation of productive skills ${ }^{25}$. In particular it is clear

\footnotetext{
${ }^{25}$ In our analysis, human capital can be accumulated only through private investments in education, and considering public education goes beyond our scopes. However, it is interesting to relate our contribution to Poutvaara (2004): in his model an increasing international applicability of a given type of education encourages private investments in this kind of skills (similar to our model, where $x$ increases with $m$ ), but "... governments face an incentive to divert the provision of public education away from internationally applicable education toward country-specific skills. This would mean educating too few engineers, economists and doctors, and too many lawyers. [...] It could even allow for a Pareto-improvement". However, in Poutvaara's model, countryspecific skills are not assumed to be employed in the rent-seeking sector.
} 
that $x_{M}^{*}$ is larger than $x^{*}$ for every positive value of $m$ : as we have already put forward, easier migration puts more weight on expected income abroad, thus inducing a stronger investment in portable skills and a smaller defensive effort.

Given the optimal $(x, 1-x)$ choice, we can find the equilibrium value of $p$, equating expected profits and expected rents. In autarky, we solve:

$$
\left(1-x^{*}\right) \rho\left(x^{*}\right)^{\alpha}=\left[1-\left(1-x^{*}\right) \rho\right] \frac{1-p}{p}\left(x^{*}\right)^{\alpha},
$$

to get:

$$
p_{\epsilon}=1-\frac{\rho}{(1+\alpha)}=\frac{\alpha+(1-\rho)}{(1+\alpha)} .
$$

When migration is taken into account, the "career-arbitrage" condition

$$
\left[(1-m)\left(1-x_{M}^{*}\right) \rho+m\left(1-q_{F}\right)\right]\left(x_{M}^{*}\right)^{\alpha}=\left[1-\left(1-x_{M}^{*}\right) \rho\right] \frac{(1-p)(1-m)}{p}\left(x_{M}^{*}\right)^{\alpha}
$$

determines:

$$
p_{\epsilon, M}(m)=\frac{\alpha+(1-\rho) \frac{1-m}{1-m q_{F}}}{(1+\alpha)} .
$$

For every $m \in(0, \bar{m}), p_{\epsilon, M}$ is lower than $p_{\epsilon}$ but, to assess the moralization effect of migration, we need to look at the after-migration predator/prey ratio:

$$
\gamma_{\epsilon, M}(m)=\frac{p_{\epsilon, M}}{\left(1-p_{\epsilon, M}\right)(1-m)}=\frac{\alpha}{(1-m)}+\frac{(1+\alpha)(1-\rho)}{(1-m) \rho+m\left(1-q_{F}\right)} .
$$

The following Proposition would then hold:

Proposition 3 Provided that $\rho$ is low enough, the "moralization" effect of probabilistic migration is preserved also under the assumption of endogenous protection.

To see that, consider $\gamma_{\epsilon, M}$ : it is decreasing in $m$, until $m=\check{m}$ where it gets a minimum. And since:

$$
\check{m}=\frac{[(1-\rho)+\alpha]\left[(1-\rho)-q_{F}\right]-\left(1-q_{F}\right) \sqrt{\alpha(1+\alpha)(1-\rho)\left[(1-\rho)-q_{F}\right]}}{\left[(1-\rho)+\alpha q_{F}\right]\left[(1-\rho)-q_{F}\right]},
$$

then: $\check{m}<\bar{m}$ for $\rho>\left[\sqrt{\alpha(1+\alpha)\left(1-q_{F}\right)+\left(\alpha q_{F} / 2\right)^{2}}-\alpha\left(1-q_{F} / 2\right)\right]$.

This result means that for low enough $\rho^{\prime}$ s, the predator/prey ratio is decreasing for every admissible value of $m$, i.e. $\forall m \in(0, \bar{m})$; non-monotonicity occurs only for higher values of $\rho$. In the specific case of a rent-free destination country $\left(q_{F}=0\right)$, we would have that $\bar{m}=\rho /(\alpha+\rho)$ and $\gamma_{\epsilon, M}(m)$ is monotonically decreasing in $m$ as long as $\rho \leq$ $\sqrt{\alpha(1+\alpha)}-\alpha$. Let us just recall that $\rho$ measures the opportunity cost of of diverting some resources from defense to accumulation of productive capital; when both $\rho$ and $m$ are large, property becomes poorly protected in the sending economy, since $x$ is also high and this has a sizable effect on $q$ : this implies that the expected income of entrepreneurs is heavily affected and the moralization effect stops working. 


\subsection{The optimal migration rate}

Let us now see if a positive optimal (income-maximizing) emigration rate $m^{*}$ does exist, when protection is assumed to be endogenous.

In straight analogy with the case of exogenous protection, and keeping in mind that $x_{M}^{*}$ is in turn a function of $m$, the quantity to be maximized may be one of the following:

(i') the after-migration total income of high-skilled producers (obviously, net of rent-seeking), given by: $\Psi_{M}(m)=(1-m)\left(1-p_{\epsilon, M}\left(x_{M}^{*}\right)\right)\left(1-q\left(x_{M}^{*}\right)\right)\left(x_{M}^{*}\right)^{\alpha}$;

(ii') the after-migration average income of "honest" producers, i.e.:

$$
\frac{(1-m)\left[1-p_{\epsilon, M}\left(x_{M}^{*}\right)\right]\left(1-q\left(x_{M}^{*}\right)\right) h\left(x_{M}^{*}\right)}{(1-m)\left[1-p_{\epsilon, M}\left(x_{M}^{*}\right)\right]+\chi} .
$$

Let us consider the case with $q_{F}=0$ : with an exogenous extortion rate $q$ (see previous Section), we were ensured that a strictly positive $m^{*}$ did exist. Under endogenous protection, things change; in fact, we can prove the following:

Proposition 4 If protection is endogenous and migration is directed to a rent-free economy, a strictly positive value for $m^{*}$ may not exist if $\rho$ exceeds a critical value $\underline{\rho}$.

The claim of the above Proposition is easy to prove for function (i'). From $\partial \Psi_{M}(m) / \partial m=0$ (with $\partial^{2} \Psi_{M}(m) / \partial m^{2}<0$ ), we obtain:

$$
m^{*}=\frac{2 \alpha(1-\rho)+\rho(3-4 \rho)+\alpha^{2}-\sqrt{\kappa}}{4(1-\rho)(\alpha+\rho)},
$$

where $\kappa=\alpha^{2}(2+\alpha)^{2}-2 \alpha \rho\left[2\left(\alpha^{2}-1\right)+\alpha\right]-\rho^{2}[4 \alpha(1+\alpha)-1]$.

It is easy to check that $\partial m^{*} / \partial \rho<0$ : the optimal migration decreases with $\rho$. In particular, for $m^{*}$ to be strictly positive, we need simply that $\rho<1 / 2=\rho$. Therefore, for $\rho \geq 1 / 2$, $m^{*}$ would be equal to zero: if the sending economy is able to control its migration rate, the optimal policy choice should be to keep its frontiers closed.

Furthermore, the condition $\rho<1 / 2$ warrants the existence of a strictly positive value of $m$ (call it $\hat{m})$, which maximizes the absolute number of skilled workers not engaged in rent-seeking, given by $(1-m)\left(1-p_{\epsilon, M}\left(x_{M}^{*}\right)\right)^{26}$. Just notice that $m^{*}<\hat{m}^{27}$, and $\partial \hat{m} / \partial \rho<0$.

As it will be proved in Appendix A, the claim of Proposition 4 applies also to case (ii'), while it cannot be extended to an objective function which includes rent-seeking incomes ${ }^{28}$ (see Appendix B).

\footnotetext{
${ }^{26}$ Maximizing this product is probably a more natural extension of (i) than ( $\left.i^{\prime}\right)$, but it would miss the point that the accumulation of productive resources is now endogenous, as well as the fraction of these resources that is protected from rent-seeking.

${ }^{27}$ Both $m^{*}$ and $\hat{m}$ are equal to zero, when $\rho=1 / 2$.

${ }^{28}$ In such a case a strictly positive $m^{*}$ does always exist. This result is not surprising: with endogenous protection, productive workers produce more ( $h$ is higher) and set up weaker defenses (higher extortion rate $q$ ); as a consequence, a rent-seeker who comes in contact with an entrepreneur obtains a higher rent. In addition, as was already the case with an exogenous $q$, rent-seekers also benefit from migration as long as the predator/prey ratio decreases, there is less crowding-in and their chance to meet a productive worker increases.
} 
This set of results (Propositions 3 and 4) conveys the message that, roughly speaking, migration can better solve the rent-seeking problem, thereby improving economic performance, only if the opportunity cost of diverting some resources (time) from protection to accumulation of productive capital is not very high. If it is not the case $(\rho \geq 1 / 2)$, the general result drawn from Section 3 is completely reversed: inducing weaker institutions and less effective defense against rent-seeking, migration turns out to be harmful for economic performance; the best policy option, for the developing country, would be to close its frontiers to migration outflows.

\section{Endogenous migration rate}

Throughout the previous Section, we have assumed the probability of migration for productive workers to be fixed at the level $m$, regardless of $h$ and $x$. Indeed, it could be the case that the chance of emigration is higher when the human capital of the prospective migrant is higher. Some destination countries, for instance, tend to select immigrants by skills: people with more years of education are more likely to be accepted.

To take this possibility into account, we can consider the probability of migration at time $t+1$ as being a function of the investment in productive skills made at time $t$; neglecting time indexes, we would have $m=z(x)$. For the sake of simplicity, we choose a linear specification for $z(x)$, such that $m=\sigma x$, with $0 \leq \sigma \leq 1$ : the probability of migration increases linearly with the quantity of time spent building up productive skills.

The parameter $\sigma$ measures how efficiently education is transformed into a positive chance to emigrate; in this framework, an increase in $\sigma$ would correspond ceteris paribus to an increased mobility of workers: for any given value of $x$, a higher $\sigma$ translates into a higher probability of migration. Just notice that $\sigma=0$ corresponds to the autarkic case: the probability of migration is zero, no matter how many years have been spent accumulating human capital.

For the rest, the theoretical setup is the same as that of Section 4: in particular, we assume that the extortion rate $q$ depends positively on $x$ (endogenous protection).

In this new framework, the first thing we may want to look at is the optimal quantity of time devoted to human capital accumulation, $x_{M^{\prime}}^{*}$. With $q_{F}=0$ (rent-free destination country), it is given by:

$$
x_{M^{\prime}}^{*}=\min \left[\frac{(1+\alpha)[\rho-(1-\rho) \sigma]-\sqrt{\Lambda}}{2(2+\alpha) \rho \sigma} ; 1\right],
$$

where $\Lambda=(1+\alpha)^{2}[\rho-(1-\rho) \sigma]^{2}-4 \alpha(2+\alpha) \rho^{2} \sigma$.

Ignoring corner solutions, which can be ruled out as long as $\sigma<\rho /(1+\alpha+\rho)$, we can check that $\partial x_{M^{\prime}}^{*} / \partial \sigma>0$; when $\sigma$ increases, productive workers will invest more in education, since: (i) $x$ becomes more decisive in determining their probability of migration, and (ii) a higher probability of migration raises expected returns to education. 
This result parallels the one obtained in Section 4 , where the optimal $x$ was a positive function of $m$. Moreover we can see that, for $\sigma=0$, the autarkic result with endogenous protection is reproduced, in fact $\lim _{\sigma \rightarrow 0} x_{M^{\prime}}^{*}=\alpha /(1-\alpha)$ (as in expression (9)).

Equating profits and rents, we obtain the equilibrium allocation of talent (the endogenous size of the two groups) as a function of the parameter $\sigma$; before migration takes place, the proportion $p_{\epsilon, M^{\prime}}(\sigma)$ of people engaging in a rent-seeking career is given by:

$$
\frac{\rho\left\{\rho\left[1+\alpha(\sigma-1)^{2}-(6-\sigma) \sigma\right]-2 \sigma[\sigma-3+\alpha(\sigma-\alpha-3)]-(1+\sigma) \sqrt{\Lambda}\right\}+\sigma[\sigma(1+\alpha)+\sqrt{\Lambda}]}{2(2+\alpha)^{2} \rho \sigma} .
$$

Not surprisingly, we have that $\lim _{\sigma \rightarrow 0} p_{\epsilon, M^{\prime}}(\sigma)=(\alpha+1-\rho) /(1+\alpha)=p_{\epsilon}$ (autarky). But it is very important to notice that, in sharp contrast with our previous analysis, an increased mobility of skilled workers does not reduce the fraction of educated agents involved in rent-seeking activities. In fact, $\partial p_{\epsilon, M^{\prime}}(\sigma) / \partial \sigma$ is always positive ${ }^{29}$ (see Appendix $C$ for a proof) while, in the case of exogenous migration, we had $\partial p_{M}(m) / \partial m<0$.

To understand how this result is determined, consider that when $m$ is endogenous ( $m=$ $\sigma x)$, an increase in $\sigma$ will push productive workers to invest more in $x$ (as stated above); a larger $x$, however, will determine weaker protection, i.e. a higher extortion rate $q$. This lack of protection will affect heavily the income of those productive agents who cannot migrate: although the prospective income of successful migrants benefits from higher values of $x$ and $\sigma$, the expected income of productive workers (which is an average of the two) will not raise that much. On the other hand, the expected income of rent-seekers shifts up notably, whatever $p$, since the higher extortion rate $q$ more than compensates a tougher crowdingin (larger $m$ ). To sum up, both expected profits and expected rents increase; however, the former shifts up by less, thus determining a lower $p^{30}$.

Therefore, we have a first clue that the moralization effect of migration might not hold any more, if the probability of migration is endogenous. Such an hypothesis is confirmed by the inspection of the after-migration predator/prey ratio $\gamma_{\epsilon, M^{\prime}}(\sigma)=p_{\epsilon, M^{\prime}}(\sigma) /[(1-$ $\left.\left.p_{\epsilon, M^{\prime}}(\sigma)\right)(1-m(\sigma))\right]$, which is given by:

$\frac{\rho^{2}[1+\alpha-(3+\alpha) \rho]+2 \rho(\rho-1)[1+\alpha+(2+\alpha) \rho] \sigma-(1+\alpha)(\rho-1)^{3} \sigma^{2}+\left[\rho(1+\rho)-(\rho-1)^{2} \sigma\right] \sqrt{\Lambda}}{2 \rho\left[\rho^{2}(\sigma-1)^{2}+\sigma^{2}-2 \rho \sigma(1+\sigma)\right]}$.

In fact, after checking that $\lim _{\sigma \rightarrow 0} \gamma_{\epsilon, M^{\prime}}(\sigma)=\alpha+(1+\alpha)(1-\rho) / \rho=\gamma_{\epsilon}=\lim _{m \rightarrow 0} \gamma_{\epsilon, M}(m)$, we can also see (Appendix C) that $\gamma_{\epsilon, M^{\prime}}(\sigma)$ is always increasing in $\sigma$. Therefore:

Proposition 5 When the probability of migration depends on skill accumulation, an increased mobility of workers does not induce any moralization effect in the sending country.

\footnotetext{
${ }^{29}$ For the sake of completeness, consider that a corner solution $\left(x_{M^{\prime}}^{*}=1\right)$ would determine $p_{\epsilon, M^{\prime}}(\sigma)=1-\sigma$, so that the result is reversed.

${ }^{30}$ Recall that the equilibrium value of $p$ is found as the intersection of the two curves representing expected profits and expected rent-seeking income, respectively.
} 
In analogy with our previous analysis, we would also be interested in assessing whether an optimal migration rate exists. However, migration is now endogenous, and then we may ask whether a strictly positive optimal value for $\sigma$ (the exogenous parameter affecting $m$ ) exists. For the sake of analytical tractability, we consider only the following objective function:

$$
\Xi_{M^{\prime}}(\sigma)=\left(1-m\left(x_{M^{\prime}}^{*}\right)\right)\left(1-p_{\epsilon, M^{\prime}}\left(x_{M^{\prime}}^{*}\right)\right)\left(1-q\left(x_{M^{\prime}}^{*}\right)\right)\left(x_{M^{\prime}}^{*}\right)^{\alpha},
$$

where $x_{M^{\prime}}^{*}$ is a function of $\sigma$, as we know from (19). The above expression represents the after-migration total income of high-skilled producers, and corresponds to cases (i) and (i') in Sections 3 and 4.

It is immediately evident that the first three terms of the four that concur to determine $\Xi_{M^{\prime}}(\sigma)$ are decreasing in $\sigma$. Therefore, it is unlikely that a strictly positive $\sigma^{*}$ may exist. Although we cannot prove it analytically, in Appendix $C$ we will use numerical simulations to show that $\Xi_{M^{\prime}}(\sigma)$ is monotonically decreasing in $\sigma$ for a wide range of parameter values.

Therefore, if the probability of migration depends on human capital, opening frontiers unambiguously hurts the sending economy ${ }^{31}$.

We can now summarize our theoretical results. When the probability of migration does not depend on skills, a strictly positive optimal migration rate $m^{*}$ always exists with exogenous protection, while it exists only for some parameter configurations under endogenous protection. Similarly, migration always induces a more favorable allocation of talent with exogenous protection, and for values of $m$ which are not too large in the case of endogenous protection. However, if protection is endogenous and the likelihood of migration depends on human capital accumulation, the moralization effect disappears and there is no strictly positive optimal value for $\sigma$, i.e. for the parameter that determines the migration chance $m$.

\section{Conclusions}

In this paper we have explored the interplay between probabilistic migration and the endogenous allocation of talent, as well as its consequences for economic performance in the concerned country.

We started by presenting some stylized facts. Across countries, the skilled migration rate appears to be positively (negatively) correlated with the fraction of educated agents who specialize in productive (rent-seeking) fields. However, we see that this kind of correlation is not preserved if instead of the relative size of parasitic and productive groups we

\footnotetext{
${ }^{31}$ It is important to underline that our representation of an endogenous probability of migration considers all the agents who have access to human capital enhancement as being the same vis-à-vis their educational possibilities. It would be more realistic to introduce some heterogeneity, through a distribution of innate abilities in transforming $x$ in $h$, and deal with the possible self-selection of migrants, but the model would be extremely difficult to handle. Therefore, we propose to interpret our model as a polar case, useful to show how shifting from random to endogenous migration affects the relationship between labor mobility and rent-seeking.
} 
consider the total amount of rent-seeking, that we measure through a perceived corruption index and which also involves an appreciation of rent-seeking intensity.

Then, we have built a simple model showing how, on purely theoretical grounds, probabilistic migration can be expected to induce a moralizing effect in an economy affected by a severe problem of rent-seeking and corruption: in such a case a positive incomemaximizing migration rate can be identified.

However, we have also pointed out that these quite optimistic findings rest on an admittedly simple assumption, namely that the effectiveness of rent-seeking is exogenously determined. In fact, this kind of result may be weakened or may not hold any more once endogenous protection is taken into account, depending on how efficiently productive agents can manage to defend themselves against rent-seekers, and possibly on the quality of institutions and political culture in the developing country. Moreover, if not only protection but also migration is made endogenous, there is even less room for a positive role of skilled labor mobility in the perspective of reducing rent-seeking.

As interesting extensions, and possible directions for further research, we would suggest: (i) to explore the growth implications of migration in a OLG model with joint rentseeking/income dynamics, (ii) to analyze possible strategic complementarities between bureaucratic behavior and innovation, (iii) to endogenize the skill distribution of productive workers, and (iv) to endogenize the offensive effort of rent-seekers (prospecting a decrease in rents due to the lack of potential prey, migration may induce parasitic agents to soften their pressure on productive workers).

\section{References}

[1] Acemoglu, D. (1995): "Reward structures and the allocation of talent", European Economic Review 39, 17-33.

[2] Baland, J.-M. and P. François (2000): "Rent-seeking and resource booms", Journal of Development Economics 61, 527-542.

[3] Bardhan, P. (1997): "Corruption and development: a review of issues", Journal of Economic Literature 35, 1320-1346.

[4] Baumol, W.J. (1990): "Entrepreneurship: productive, unproductive, and destructive", Journal of Political Economy 98 (5), 893-921.

[5] Beine, M., F. Docquier and H. Rapoport (2001): "Brain drain and economic growth: theory and evidence", Journal of Development Economics 64, 275-289.

[6] Bhagwati, J.N. and K. Hamada (1974): "The brain drain, international integration of markets for professionals and unemployment", Journal of Development Economics 1, 1942. 
[7] Docquier, F. and A. Marfouk (2004): "Measuring the international mobility of skilled workers (1990-2000) - Release 1.0", World Bank Policy Research Working Paper 3381.

[8] Docquier, F. and H. Rapoport (2003a): "Ethnic discrimination and the migration of skilled labor", Journal of Development Economics 70, 159-172.

[9] Docquier, F. and H. Rapoport (2003b): "Endogenous discrimination, migration and the protection of ethnic minorities", Annales d'Economie et de Statistique 71/72, 79-95.

[10] Grossman, H.I. and M. Kim (1995): "Swords or plowshares? A theory of the security of claims to property", Journal of Political Economy 103 (6), 1275-1288.

[11] Mehlum, H., K. Moene and R. Torvik (2003): "Predator or prey? Parasitic enterprises in economic development", European Economic Review 47, 275-294.

[12] Mauro, P. (1995): "Corruption and growth", Quarterly Journal of Economics 110 (3), 681712.

[13] Mountford, A. (1997): "Can a brain drain be good for growth in the source economy?", Journal of Development Economics 53, 287-303.

[14] Murphy, K.M., A. Shleifer and R.W. Vishny (1991): "The allocation of talent: implications for growth", Quarterly Journal of Economics 106 (2), 503-530.

[15] Murphy, K.M., A. Shleifer and R.W. Vishny (1993): "Why is rent-seeking so costly to growth?", American Economic Review 83 (2), 409-414.

[16] Poutvaara, P. (2004): "Public education in an integrated Europe: studying to migrate and teaching to stay?", CESifo Working Paper 1369.

[17] Stark, O. and Y. Wang (2002): "Inducing human capital formation: migration as a substitute for subsidies", Journal of Public Economics 86, 29-46.

[18] Torvik, R. (2002): "Natural resources, rent seeking and welfare", Journal of Development Economics 67, 455-470.

[19] UNESCO (1998, 1999, 2006): Statistical Yearbook. [Most recent data are available on-line at: http://stats.uis.unesco.org/ReportFolders]

\section{A Existence of a strictly positive $m^{*}$ with endogenous protection (Proposition 4)}

In Section 4, we have already shown under which conditions a strictly positive $m^{*}$ does exist, when the objective function is specified as in ( $\left.i^{\prime}\right)$. Let us now consider function (ii'): in this case it is not possible to obtain an analytical expression for $m^{*}$. In fact, calling 
$\Phi_{M}(m)$ the after-migration average income of honest producers, we see that the equation $\partial \Phi_{M}(m) / \partial m=0$ does not admit closed form solutions. However, it is possible to identify conditions under which a strictly positive $m^{*}$ may exist.

After recalling that in Section 4 we assumed $m<\rho /\left[\alpha\left(1-q_{F}\right)+\rho\right]$ to rule out corner solutions, and that we are now working with $q_{F}=0$, it is easy to check that:

$$
\lim _{m \rightarrow 0} \frac{\partial \Phi_{M}(m)}{\partial m}=\left(\frac{\alpha}{1+\alpha}\right)^{\alpha} \frac{\rho(1-2 \rho) \chi}{[\rho+\chi(1+\alpha)]^{2}}
$$

and

$$
\lim _{m \rightarrow \rho /(\alpha+\rho)} \frac{\partial \Phi_{M}(m)}{\partial m}=-\frac{\rho(\alpha+\rho)^{2}}{(1+\alpha)\left[\alpha \rho+(\alpha+\rho)^{2} \chi\right]} .
$$

It is clear that the second limit is always negative. If the first limit is positive, and that is the case as long as $\rho<1 / 2$, we are ensured that $0<m^{*}<\rho /(\alpha+\rho)$. If $\rho \geq 1 / 2$, a strictly positive $m^{*}$ fails to exist.

\section{B An alternative specification for the social objective function: the after-migration average income (including rents)}

The results we have obtained in Section 3 and 4 were based on the assumption that the utility of rent-seekers should not be included in the social objective function. However, this needs not necessarily be the case. Suppose in fact that the identity of rent-seekers and entrepreneurs is anonymous a priori and thus the social planner feels committed to maximizing the well-being of the whole population, regardless of their career choice. In such a case an appropriate objective function would be the after-migration average income (including rents in the count).

\section{B.1 Exogenous protection}

Assuming for the moment that the extortion rate $q$ is exogenous, the objective function writes as:

$$
\frac{\left\{(1-m)\left[1-p_{M}(m)\right](1-q)+p_{M}(m)\left[(1-m)\left(1-p_{M}(m)\right) / p_{M}(m)\right] q\right\} h}{(1-m)\left[1-p_{M}(m)\right]+p_{M}(m)+\chi}
$$

the optimal migration rate is then given by:

$$
m^{*^{\prime}}=\max \left[0 ; \frac{q+\chi-\left(1-q_{F}\right) \sqrt{\frac{q \chi(1+\chi)}{q-q_{F}}}}{q+\chi q_{F}}\right],
$$

that is strictly positive provided that $q_{F}<\left[q^{2}+\chi(2 q-1)\right] /[q(1+\chi)]$.

With $q_{F}=0$, we have that $m^{*^{\prime}}=[q+\chi-\sqrt{\chi(1+\chi)}] / q$; this optimal $m$ is always positive, since we assumed $q>1 / 2$. 
It is worth noting that $m^{*^{\prime}}$, like $m^{*}$ (as given by (7)), is increasing in $q$ : the higher the extortion rate in the sending economy, the larger the optimal migration rate. Not surprisingly, we can also check that $m^{*^{\prime}}>m^{*}$. This depends on the fact that, when adding rent-seekers to the computation of average income, there is no additional "drain effect" to be accounted for: parasitic agents do not migrate and average rents, depending directly on the predator/prey ratio (see the objective function above), are always increasing in $m$.

\section{B.2 Endogenous protection}

The suitable objective function, call it $\Theta_{M}(m)$, now becomes:

$$
\frac{\left\{(1-m)\left[1-p_{\epsilon, M}\left(x_{M}^{*}\right)\right]\left(1-q\left(x_{M}^{*}\right)\right)+p_{\epsilon, M}\left(x_{M}^{*}\right)\left[(1-m)\left(1-p_{\epsilon, M}\left(x_{M}^{*}\right)\right) / p_{\epsilon, M}\left(x_{M}^{*}\right)\right] q\left(x_{M}^{*}\right)\right\} h\left(x_{M}^{*}\right)}{(1-m)\left[1-p_{\epsilon, M}\left(x_{M}^{*}\right)\right]+p_{\epsilon, M}\left(x_{M}^{*}\right)+\chi} .
$$

In this case it is not possible to obtain an analytical expression for the optimal migration rate $m^{*^{\prime}}$, since the equation $\partial \Theta_{M}(m) / \partial m=0$ does not admit closed form solutions.

However, it is possible to identify conditions under which a strictly positive $m^{*^{\prime}}$ exists. In fact, assuming that $q_{F}=0$, it can be shown that:

$$
\lim _{m \rightarrow 0} \frac{\partial \Theta_{M}(m)}{\partial m}=\frac{\alpha^{\alpha}(1+\alpha)^{-\alpha-2}\left[(1+\alpha-\rho)^{2}+(1+\alpha)(1+\alpha-2 \rho) \chi\right]}{(1+\chi)^{2}}
$$

and

$$
\lim _{m \rightarrow \rho /(\alpha+\rho)} \frac{\partial \Theta_{M}(m)}{\partial m}=\frac{(\alpha+\rho)^{2}\left[\alpha\left(\alpha+\alpha^{2}-\rho^{2}\right)+(1+\alpha)(\alpha-\rho)(\alpha+\rho) \chi\right]}{(1+\alpha)\left[\alpha(\alpha+2 \rho)+(\alpha+\rho)^{2} \chi\right]^{2}} .
$$

A sufficient condition for the first limit to be positive is that $\rho<(1+\alpha) / 2$. But this coincides with the restriction $\rho<\bar{\rho}$ in Section 4 . We are then ensured that $m^{*{ }^{\prime}}$ is strictly positive, as long as corner solutions are ruled out. Moreover, if $\rho>\alpha \sqrt{(1+\alpha)(1+\chi) /[\alpha+(1+\alpha) \chi]}$ the second limit is negative, and we are sure that $0<m^{*}<\rho /(\alpha+\rho)$.

Therefore, Proposition 4 does not hold any more if the objective function includes rents as well. To understand why, consider that when protection is endogenous, productive workers produce more ( $h$ is higher) and set up weaker defenses (higher extortion rate $q$ ); as a consequence, a rent-seeker who comes in contact with an entrepreneur is able to obtain a higher rent. Moreover, as was already the case with an exogenous $q$, rent-seekers also benefit from migration as long as the predator/prey ratio decreases, there is less crowdingin and the probability to meet a productive worker increases. From the viewpoint of a policy maker who also cares about rent-seekers' welfare, the optimal $m$ would never be 0 .

\section{Endogenous migration: proofs and numerical simulations}

First, we want to prove that both $p_{\epsilon, M^{\prime}}(\sigma)$ and $\gamma_{\epsilon, M^{\prime}}(\sigma)$ (as defined in Section 5) are increasing in $\sigma$. For ease of exposition, we will present our computations in the case of $\alpha=1$. However, our results fully generalize to other values of $\alpha$ between 0 and 1 . 
We can write:

$$
\frac{\partial p_{\epsilon, M^{\prime}}(\sigma)}{\partial \sigma}=-\frac{[\rho(\sigma-1)-\sigma]\left\{2 \rho^{2}+(\rho-4) \rho \sigma+2(\rho-1)^{2} \sigma^{2}-2[\rho+(\rho-1) \sigma] \sqrt{\zeta}\right\}}{18 \rho \sigma^{2} \sqrt{\zeta}},
$$

where $\zeta=[\rho+(\rho-1) \sigma]^{2}-3 \rho^{2} \sigma$.

For derivative (23) to be positive, we need $\sigma>\rho /(\rho-1)$, which is always verified with $\rho<1$, since $\sigma$ is assumed to take positive values.

A fortiori, also $\gamma_{\epsilon, M^{\prime}}(\sigma)$ is increasing in $\sigma$. In fact:

$$
\gamma_{\epsilon, M^{\prime}}(\sigma)=\frac{p_{\epsilon, M^{\prime}}(\sigma)}{\left(1-p_{\epsilon, M^{\prime}}(\sigma)\right)(1-m(\sigma))^{\prime}}
$$

and we have already proved that the numerator $p_{\epsilon, M^{\prime}}(\sigma)$ increases with $\sigma$, while the denominator is a negative function of $\sigma$.

In addition, we present the output of some numerical simulations, in order to show that a strictly positive value of $\sigma$ which maximizes function $\Xi_{M^{\prime}}(\sigma)$ (as specified in Section 5) seems not to exist.

After fixing $\rho=0.4$, in Figure 6 we have drawn $\Xi_{M^{\prime}}(\sigma)$ for $\alpha=0.2, \alpha=0.55$ and $\alpha=0.9$, respectively. In all cases, $\Xi_{M^{\prime}}(\sigma)$ is monotonically decreasing in $\sigma$. This holds true for every $0<\alpha \leq 1$, and whatever $\rho$.

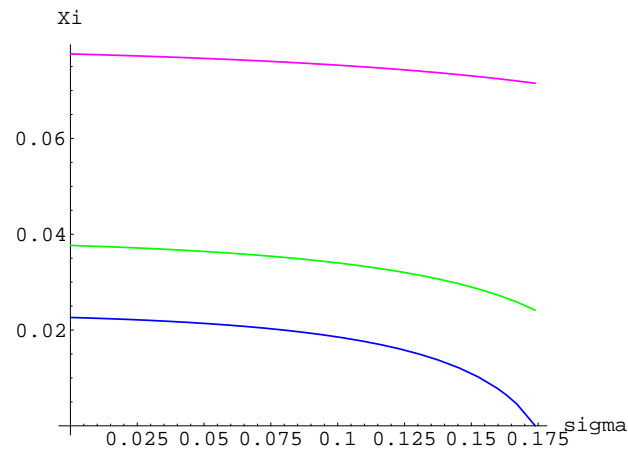

Figure 6: The function $\Xi_{M^{\prime}}(\sigma)$

Although we are not able to prove it analytically, it is then possible to say that a strictly positive $\sigma^{*}$ should not exist. This stands in sharp contrast with the results we obtained throughout Sections 3 and 4 (exogenous protection). 